\title{
BMJ Global Health Ending TB in Southeast Asia: current resources are not enough
}

\author{
Vineet Bhatia, ${ }^{1}$ Rahul Srivastava, ${ }^{1} \mathrm{~K}$ Srikanth Reddy, ${ }^{2}$ Mukta Sharma, ${ }^{1}$ \\ Partha Pratim Mandal, ${ }^{1}$ Natasha Chhabra ${ }^{3}$ Shubhi Jhalani, ${ }^{4}$ Sandip Mandal, ${ }^{5}$ \\ Nimalan Arinaminpathy, ${ }^{6}$ Tjandra Yoga Aditama, ${ }^{1}$ Swarup Sarkar (i) ${ }^{7}$
}

To cite: Bhatia V, Srivastava $R$ Reddy KS, et al. Ending TB in Southeast Asia: current resources are not enough. BMJ Global Health 2020;5:e002073. doi:10.1136/ bmjgh-2019-002073

Handling editor Seye Abimbola

Received 15 0ctober 2019 Revised 10 December 2019 Accepted 9 January 2020

\section{Check for updates}

(c) Author(s) (or their employer(s)) 2020. Re-use permitted under CC BY-NC. No commercial re-use. See rights and permissions. Published by BMJ.

${ }^{1}$ Department of Communicable Diseases, World Health Organization Regional Office for South-East Asia, New Delhi, India

Bruyere Research Institute Ottawa, Ontario, Canada ${ }^{3}$ Department of Sociology, University of Maryland Baltimore, Baltimore, Maryland, USA

${ }^{4}$ Knowledge Centre, Indian Institute of Management Shillong, Shillong, India ${ }^{5}$ Translational Global Health Policy Research Cell, Indian Council of Medical Research, New Delhi, India

${ }^{6}$ School of Public Health, Imperial College London, London, UK

${ }^{7}$ Department of Health Research, Indian Council of Medical Research, New Delhi, India

Correspondence to Dr Swarup Sarkar; sarkar.swarup@gmail.com

\section{ABSTRACT}

The Southeast Asia Region continues to battle tuberculosis (TB) as one of its most severe health and development challenges. Unless there is a substantial increase in investments for TB prevention, diagnosis, care and treatment, there will be catastrophic effects for the region. The uncontrolled TB burden impacts socioeconomic development and increase of drug resistance in the region. Based on epidemiological inputs from a mathematical model, a costing analysis estimates that the desired targets of ending TB are achievable with additional interventions, and critical thresholds require an increase in spending by almost double the current levels. The data source for financial allocation to TB programmes is the report submitted by countries to WHO, while projections are based on modelling. The model accounts for funding needs for all strategies based on published data and accounts for programme and patient costs. This paper delineates the resource needs, availability and gaps of ending TB in the region. It is estimated that close to US\$2 billion per year are needed in the region for TB-related activities for a meaningful bending of the incidence curve towards ending TB.

\section{INTRODUCTION}

Despite a declining trend of tuberculosis (TB) incidence in 2018, the incidence in WHO Southeast Asia Region (WHO SEAR) remains high. ${ }^{12}$ WHO SEAR has 11 member states-Bangladesh, Bhutan, Democratic People's Republic of Korea, India, Indonesia, Maldives, Myanmar, Nepal, Sri Lanka, Thailand and Timor-Leste. Close to half of all new TB cases worldwide and more than $50 \%$ of TB deaths globally (excluding those due to TB-HIV coinfection) are accounted for by this region. ${ }^{2-4} \mathrm{~TB}$ is also the leading cause for disability-adjusted life years (DALYs) lost among people in the region among all communicable diseases, affecting the productive age group of the countries in SEAR. ${ }^{5}$ Without TB elimination in SEAR, there will be no global TB elimination. ${ }^{6}$

WHO estimated a US\$3.5 billion funding shortfall for TB implementation in 2018 and
Summary box

The Southeast Asia Region (SEAR) of WHO, bearing the highest proportion of global tuberculosis (TB) burden, demonstrated strong political commitment in recent years to achieve the end TB targets.

- While TB resource needs estimation to meet End TB strategy targets has been undertaken at a global level, there has not been an assessment of countrylevel resource requirements in the SEAR based on newer intervention strategies.

- A renewed comprehensive package of services is needed to reach end TB targets in the region, which is estimated to cost US\$25 billion until 2030 against the current project expenditure of US\$8.3 billion (2017 baseline).

- An action package of interventions is needed to strengthen essential TB services, accelerate TB case finding and notification, and adoption of current WHO guidelines for the management of latent TB infection, through the deployment of preventive therapy.

- There is an urgent need to increase domestic investments in TB, to about US\$0.8 per capita per year on an average in the region for the interventions necessary for ending TB in the region.

over US\$2 billion for TB research globally. In 2018, during the first-ever United Nations High-Level Meeting (UNHLM) on TB, world leaders committed to mobilise US $\$ 13$ billion a year to finance TB prevention and treatment (TPT) by 2022 and US $\$ 2$ billion a year for TB research. They further stated that "immediate investment for action on TB could be a clear win for the 2030 agenda" ${ }^{7}$ Although the promises are resounding, investments are yet to be made. ${ }^{8}$ Towards making 'ending TB' a reality, the Lancet Commission on TB called for rapid and aggressive investments on targeted and proven strategies, smart investments based on sound science and accelerated research and development. ${ }^{8}$

The political will for ending $\mathrm{TB}$ was expressed at a landmark regional ministerial meeting in 2017, as all 11 member states of the WHO SEAR endorsed a 'Call for Action 
to End TB by 2030'. In addition to this, there is also a Regional Strategic Plan to End TB 2016-2020, which envisages a region 'free of TB with zero death, disease, and suffering due to TB' in alignment with the global End TB strategy. This acknowledges TB as a public health threat in the region. The most important manifestation of the political will needs to be in estimating resources required to implement proven interventions with critical coverage required to 'bend the curve' and increased spending on TB prevention and care using personcentred approaches.

Past estimations have been based on existing national strategies that were less ambitious and not based on strategies required to end $\mathrm{TB} .{ }^{9}$ Hence, there is an urgent need to estimate what resources are required to finance a response in SEAR to meet the End TB strategy targets. Continued funding shortfalls will result in preventable deaths and continued TB incidence, resulting in even larger long-term resource requirements to meet global $\mathrm{TB}$ reduction targets. This paper examines the resources needed to end TB in SEAR and the potential funding gaps that impede our progress. The costing analysis undertaken provides an assessment of the resources needed to mount a comprehensive response to meet the global end TB targets in SEAR countries. The cost calculations in this paper are additionally validated by various modelling approaches. ${ }^{10-12}$ Without the investments, targets that are estimated and the country-specific monitoring in SEAR would be unattainable.

\section{ESTIMATING RESOURCE NEED FOR ENDING TB IN THE SOUTHEAST ASIA}

In order to simulate the epidemiological impact of each of the different interventions, the paper draws on a previously published mathematical model,${ }^{9}$ calibrated to each country using available epidemiological data and WHO estimates. Here, we describe the modelling approach in outline, with further technical details available in published mathematical model. ${ }^{9}$ The model divides the population into 'compartments', reflecting stages of infection, disease and diagnosis/treatment. Flows between these compartments are captured by a series of deterministic mathematical equations. The model explicitly captures the programmatic and non-programmatic sectors, and the respective standard of TB care in these sectors. In doing so, the model also captures the implications of diagnostic delays and treatment outcomes, for overall transmission. For simplicity, the model does not have age structure, and is aggregated at the country level. However, it incorporates HIV/TB coinfection, as well as the generation and transmission of multidrug-resistant tuberculosis (MDR-TB).

Three intervention packages were examined for ending TB in SEAR: (1) strengthening basic TB services, (2) accelerating TB case finding and notification, and (3) adoption of current WHO guidelines for the management of latent TB infection (LTBI), through the deployment of preventive therapy. Each package builds on the preceding ones, in cumulative combination (see table 1).

Resource need estimation was undertaken using a unit cost approach for the above-mentioned package of intervention and population size needed to be reached for each intervention. ${ }^{9}$ It involved estimating the costs and health benefits of selected TB control and treatment interventions. Key steps include:

- Forecasting the burden of disease under current intensities of TB control and treatment, along with cases, mortality and reduced numbers of DALY's for packages of each of the seven interventions identified in WHO TB programme and recently validated in the Lancet Commission. ${ }^{8}$

- Calculate unit costs for key TB diagnostic, treatment and support interventions based on country-specific data and use of similar country data in the region in the absence of country data.

- Undertake country-level incremental cost (resource needs estimation) for each intervention based on the above unit costs and forecast occasions of service to reach end TB targets by 2030 .

- Undertake comparative analysis of intervention based on results aggregated by low-burden and high-burden countries.

- Validation of country estimates through countryspecific workshops and peer reviews.

- Epidemiological model outputs are included over a 2017-2030 incremental cost projection, with all future costs being discounted at a $3 \%$ rate. Results are presented in 2017 US dollars.

Programme costs for diagnostic procedures along with TB treatment were estimated using published studies and the global TB costing database supplied by Avenir Health https://www.avenirhealth.org/softwarespectrum.php. The occasions of diagnostic services and patient months of first-line and second-line TB treatment (to allow for incomplete treatment/loss to follow-up) forecast by the epidemiological model are multiplied by unit costs to estimate the programmelevel resources needed to implement interventions in each country. These needs are compared with baseline costs to determine incremental costs-or programme resource gap. Programme costs for each intervention are presented as a proportion of public health spending in each country and at the regional level for highburden and low-burden countries.

Seven strategies are included in the costing analysis until 2030 global targets are attained. They include strengthening of existing services using non-National TB Programme (NTP) sector engagement (including provider incentives), laboratory expansion, introduction of new diagnostics (molecular diagnostics like Xpert MTB/RIF (Cepheid, Sunnyvale, California, USA)), and NTP sector treatment improvement. Accelerating case detection includes contact tracing and community referral for high-risk groups. A preventive therapy 


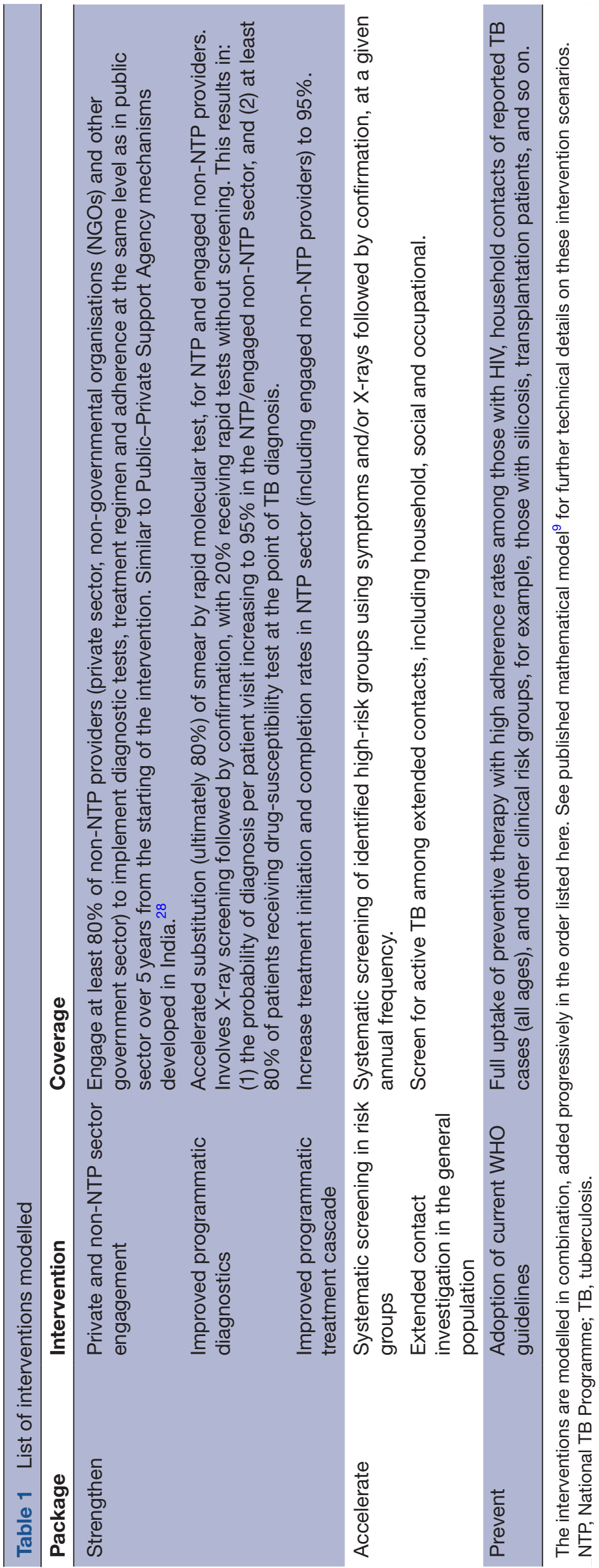


strategy is also included, in line with the most recent WHO recommendations for management of LTBI. ${ }^{13}$

Unit costs for key TB diagnostic, treatment and support interventions among WHO SEAR countries of Bangladesh, Bhutan, Democratic People's Republic of Korea, India, Indonesia, Maldives, Myanmar, Nepal, Sri Lanka, Thailand and Timor-Leste were estimated. Programme-related unit costs include medicines, tests, human resources, a capital allowance for infrastructure and a support component to capture administration and supervision. They are expressed in 2017 real terms, and as such, no allowance has been included for inflation. No distinction has been made between budget and expenditure estimates of programme unit costs.

Patient direct and indirect costs were also calculated to gauge the broader costs and benefits of implementing TB control strategies across SEAR. ${ }^{9}$ These costs are sourced from previously undertaken surveys of the costs borne by patients with TB in the region ${ }^{14} 15$ when availing $\mathrm{TB}$ diagnostic services and treatment, along with the loss of income for untreated TB and when undergoing treatment. The occasions of service, months of treatment and numbers of untreated months of TB forecast by the epidemiological model ${ }^{9}$ are multiplied by these surveyderived patient costs. Programme and patient costs are added together to calculate the total costs of each intervention strategy. Total costs are presented in aggregate, per capita and as a proportion of national per capita gross national income (GNI).

A baseline and series of incremental cost projections associated with interventions are made to calculate resource need. The numbers of presumptive patients seeking TB diagnosis, proportions diagnosed using smear, X-ray, drug-susceptibility testing and molecular diagnostics like Xpert MTB/RIF were taken from the epidemiological model and multiplied by unit costs to generate diagnostic costs. Treatment costs are estimated by multiplying months of first-line and second-line treatment outputs from the epidemiological model by estimated unit costs of treatment. ${ }^{3}$ Cost projections are made for a baseline, which assumes current coverages of diagnostic and treatment services prevail; and incremental cost scenarios involving strengthening of existing, introduction of active case finding and implementation of preventive TB services. Incremental programme costs are modelled for the seven strategies mentioned above. The incremental costs and averted burden of disease are sequentially included in the package of evaluated interventions until 2030.

Following this approach, the sequence begins with private sector engagement (PSE). The net costs and health benefits associated with this intervention is estimated relative to the baseline. Second, lab expansion is added to PSE, and a calculation of net costs and averted TB disease benefits are made. This sequence is followed until all seven strategies are included in a package that involves the introduction of preventive therapy of latent TB beginning in 2018. This package of interventions is required to meet incidence and mortality targets in the global TB strategy. This approach differs from Menzies et al, where each strategy is modelled separately, then an overall package representing a combination of all strategies is presented. ${ }^{12}$ By using this approach, it is estimated that more than 35 million TB cases will be treated between 2018 and 2030 and more than 19 million between 2018 and 2022. The anticipated achievements exceed the apportioned targets for the SEAR emanating from the UNHLM commitment to treat 40 million TB cases globally by 2022 (17.6 million based on $44 \%$ incidence burden).

\section{Patient and public involvement statement}

This research was done without patient involvement. Patients were not invited to comment on the study design and were not consulted to develop patient relevant outcomes or interpret the results. Patients were not invited to contribute to the writing or editing of this document for readability or accuracy.

\section{RESOURCE NEEDS ESTIMATES FOR THE PACKAGE OF INTERVENTIONS REQUIRED TO BE IMPLEMENTED TO END TB IN THE SEAR}

The combined cost of the four strengthening strategies (enhanced facility-based operations) represents an incremental programme resource need of around US $\$ 7$ billion for all countries until 2030 (table 2). The addition of baseline costs generates a total resource need for the four strengthening interventions of US $\$ 16$ billion or about US $\$ 1$ billion per year for the SEAR. Adding communitybased operations of contact investigations and community referral increases the resource need to US $\$ 27$ billion until 2030. The addition of each intervention is not directly cost additive, as increasing diagnosis results in decreasing treatment costs through time. The addition of preventive therapy, for example, is estimated to reduce projected treatment costs. Baseline and incremental costs can be expressed on a per capita basis, where programme funding needs are calculated relative to the national populations in each SEAR country. Average baseline annual programme spending on TB diagnosis and treatment in all SEAR is estimated at US $\$ 0.30$ per capita. There is considerable country variation in required spending per year. Requirements vary with the intensity of effort needed to reduce incidence and different costs of diagnosis and treatment in each country. Additionally, it is anticipated that the cost of preventive treatment using new shorter regimen covering all eligible population as per 2018 WHO guidelines are expected to be US $\$ 615$ million till 2030 . Only drug costs are included here because service delivery costs are assumed to be covered under intensified case finding activities when active TB is ruled out for administration of TPT (ruled in for active disease).

\section{VARIANCE OF RESOURCE NEEDS WITHIN THE REGION}

As the burden of TB differs between countries of the SEAR, there are also significant differences among 
Table 2 Programme resource needs (RN) projected estimates 2017-2030 ${ }^{29}$

\begin{tabular}{|c|c|c|c|c|}
\hline All SEAR & $\begin{array}{l}\text { Increased } \\
\text { programme } \\
\text { diagnosis cost }\end{array}$ & $\begin{array}{l}\text { Increased } \\
\text { programme } \\
\text { treatment cost }\end{array}$ & $\begin{array}{l}\text { Increased total } \\
\text { programme costs }\end{array}$ & $\begin{array}{l}\text { Total } \mathrm{RN}^{*} \text { : increased } \\
\text { programme+base } \\
\text { costs }\end{array}$ \\
\hline US\$ millions baseline (8432) & US\$ millions & US\$ millions & US\$ millions & US\$ millions \\
\hline \multicolumn{5}{|c|}{ Enhanced facility operations (EFO) } \\
\hline $\begin{array}{l}\text { +Private sector engagement } \\
\text { (PSE) }\end{array}$ & 1261.4 & 683.4 & 1944.8 & 10376.9 \\
\hline $\begin{array}{l}\text { +Laboratory expansion (LE), } \\
\text { PSE }\end{array}$ & 1164.7 & 849.5 & 2014.2 & 10446.2 \\
\hline $\begin{array}{l}\text { +New diagnostics (ND), PSE, } \\
\text { LE }\end{array}$ & 3463.3 & 4635.5 & 8098.8 & 16530.9 \\
\hline $\begin{array}{l}\text { +National TB Programme (NTP) } \\
\text { treatment, PSE, LE, ND }\end{array}$ & 2832.7 & 4475.3 & 7307.9 & 15740.0 \\
\hline \multicolumn{5}{|c|}{ Enhanced community operations+EFO } \\
\hline $\begin{array}{l}\text { +Contact tracing }(\mathrm{CT}) \text {, PSE, LE, } \\
\text { ND, NTP }\end{array}$ & 6528.0 & 4421.0 & 10949.0 & 19381.0 \\
\hline $\begin{array}{l}\text { +Community referral (CR), PSE, } \\
\text { LE, ND, NTP, CT }\end{array}$ & 13775.7 & 4322.1 & 18097.8 & 26529.9 \\
\hline $\begin{array}{l}\text { +Preventive therapy, Tuberculin } \\
\text { Skin Test (TST), PSE, LE, ND, } \\
\text { NTP, CT, CR }\end{array}$ & 0 & 614.9 & 18712.7 & 27144.8 \\
\hline
\end{tabular}

${ }^{*} \mathrm{RN}$ in this column is the total of projected baseline costs based on current trend of expenditures and the increased needs for implementation of enhanced service packages.

SEAR, Southeast Asia Region.

expenditure needs between countries (table 3). The average baseline per capita spending on TB was US $\$ 0.30$ (average of US $\$ 0.20$ in high-burden countries and US\$2.6 in low-burden, middle-income countries) in 2016. ${ }^{16}$ However, this spending needs to raise to at least US $\$ 0.80$ and the proportion of raise must be more for high-burden countries in order to achieve the comprehensive spending required to end TB in the SEAR. The average of public spending is currently at $1.3 \%$ (varying from $0.3 \%$ to $9.1 \%$ of public health expenditure) and this too must raise to $3.7 \%$ (varying from $0.5 \%$ to nearly $14 \%$ in some countries) in order for it to be effective. The average total $\%$ per capita GNI for SEAR was at $0.09 \%$ but must increase to between $0.1 \%$ and $0.2 \%$ to implement the reforms recommended. ${ }^{17}$

\section{RESOURCE AVAILABILITY FOR TB PROGRAMMES IN THE SEAR}

The total resources available in the region are about US $\$ 869$ million and the majority $(71 \%)$ of these are domestically funded (see table 4). Among the highburden countries, the majority of spending on TB comes from donors, with the Global Fund for AIDS, TB and Malaria leading the expenditure. Thailand is the only high-burden country with high domestic spending on $\mathrm{TB}$ in the region. India has increased its domestic spending almost threefold since 2016. Maldives has the highest per capita expenditure (US\$943 per capita) on TB while Bangladesh has the lowest (US\$32 per capita).
Among the high-burden countries, Thailand again has the highest per capita expenditure of US $\$ 217$.

As can be seen in table 5, the actual available budget for countries against the allocated budget varied considerably. It was as low as $13 \%$ for DPR Korea, mainly because of cessation of Global Fund support. However, in Maldives and Timor-Leste, it was more than what was budgeted. These being smaller budget countries, small variations have potentially large differences in relative terms at the country level. Expenditures against available budget varied between $70 \%$ and $100 \%$.

\section{RESOURCE GAPS OF TB CONTROL AND TREATMENT INTERVENTIONS IN THE SEAR}

As can be seen from the table 6 , the financing for TB interventions must increase drastically to end the $\mathrm{TB}$ epidemic. The total budget needs for ending TB in the SEAR is estimated at US $\$ 1.9$ billion, making the gap of about US $\$ 1$ billion in the region. Major resource gaps exist for TB high-burden countries like Bangladesh, India, Indonesia, Myanmar and Thailand. Among the low-burden countries, Sri Lanka has the highest resource gap of US\$25 million (figure 1). In the context of funding for National Strategic Plan, countries like Thailand, Myanmar and Indonesia have large unfunded gaps in their TB programmes (54\%, $27 \%$ and $24 \%$, respectively). India's unfunded percentage against the budget stands at 0 as it has been able to successfully generate funding 


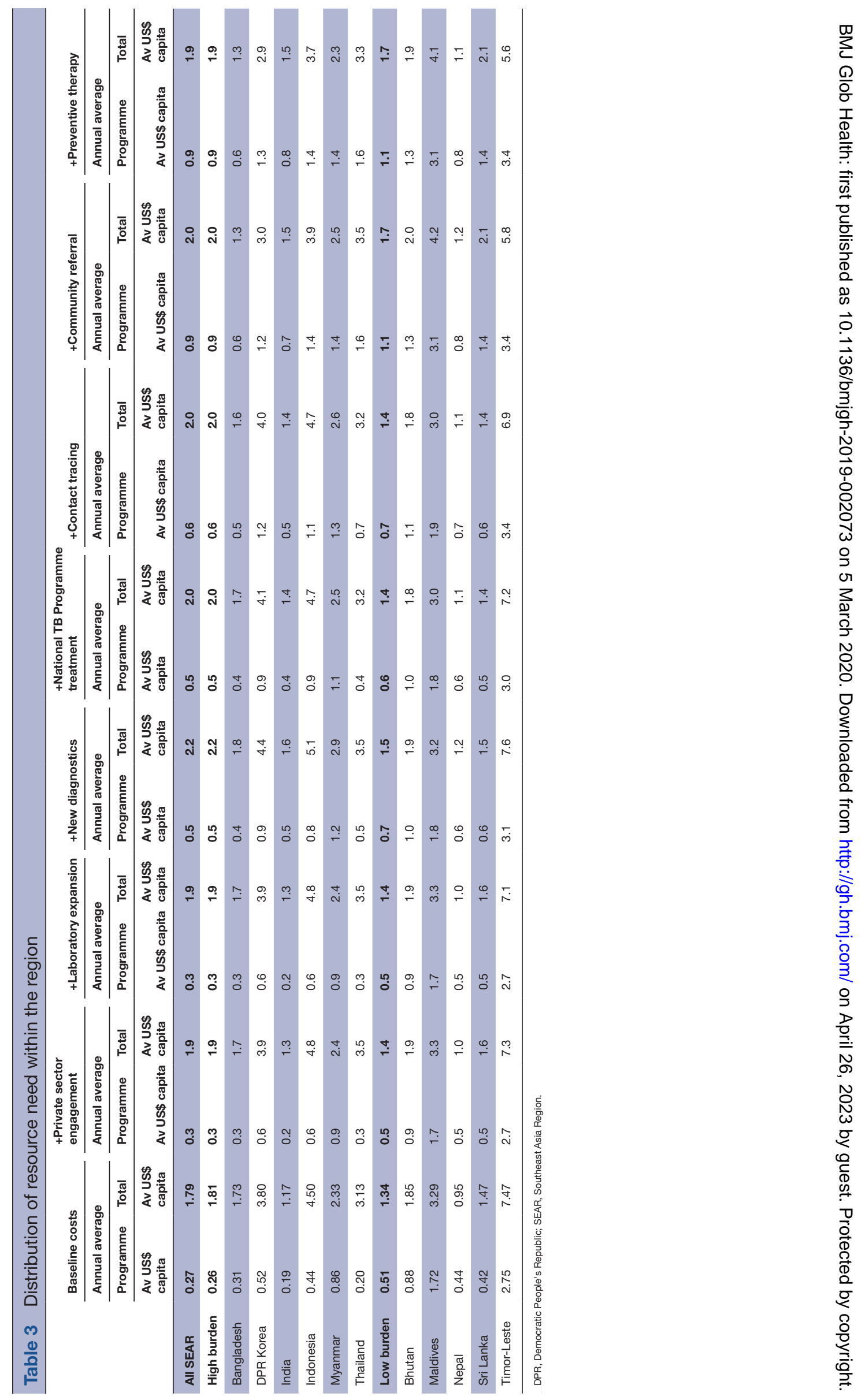




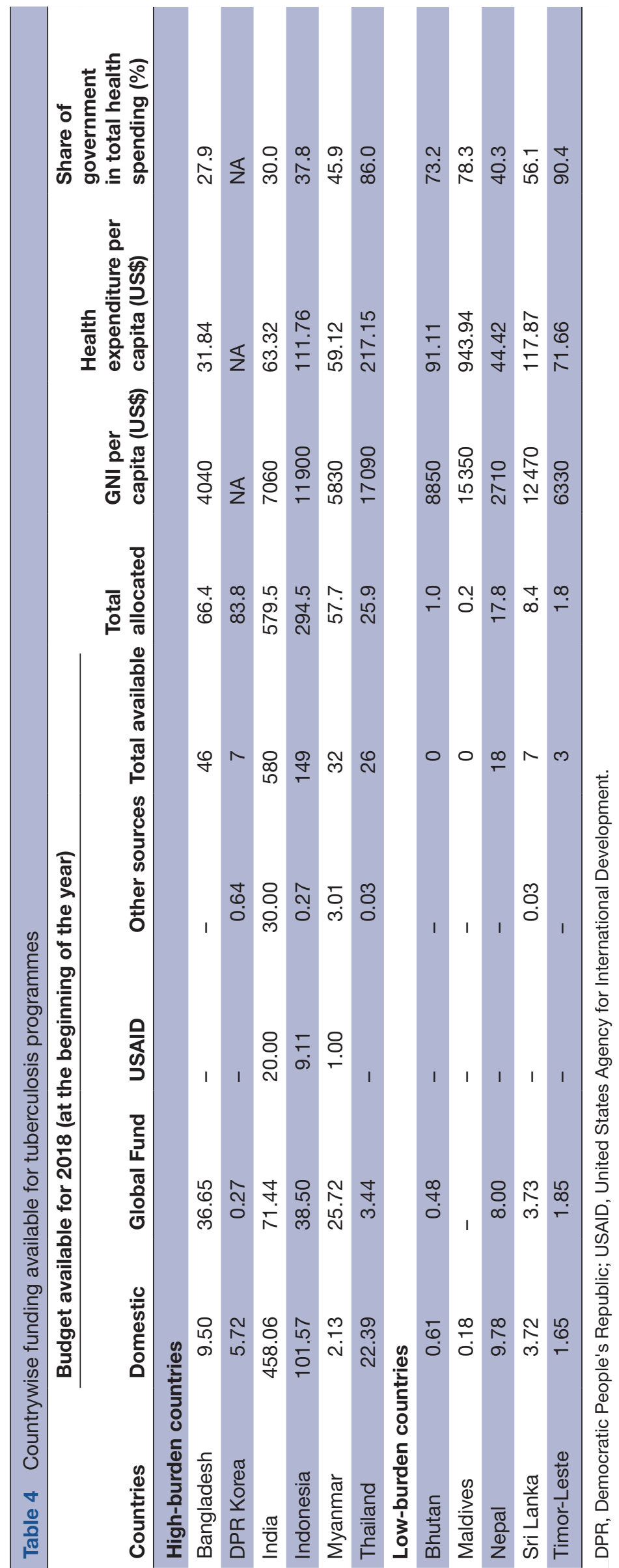




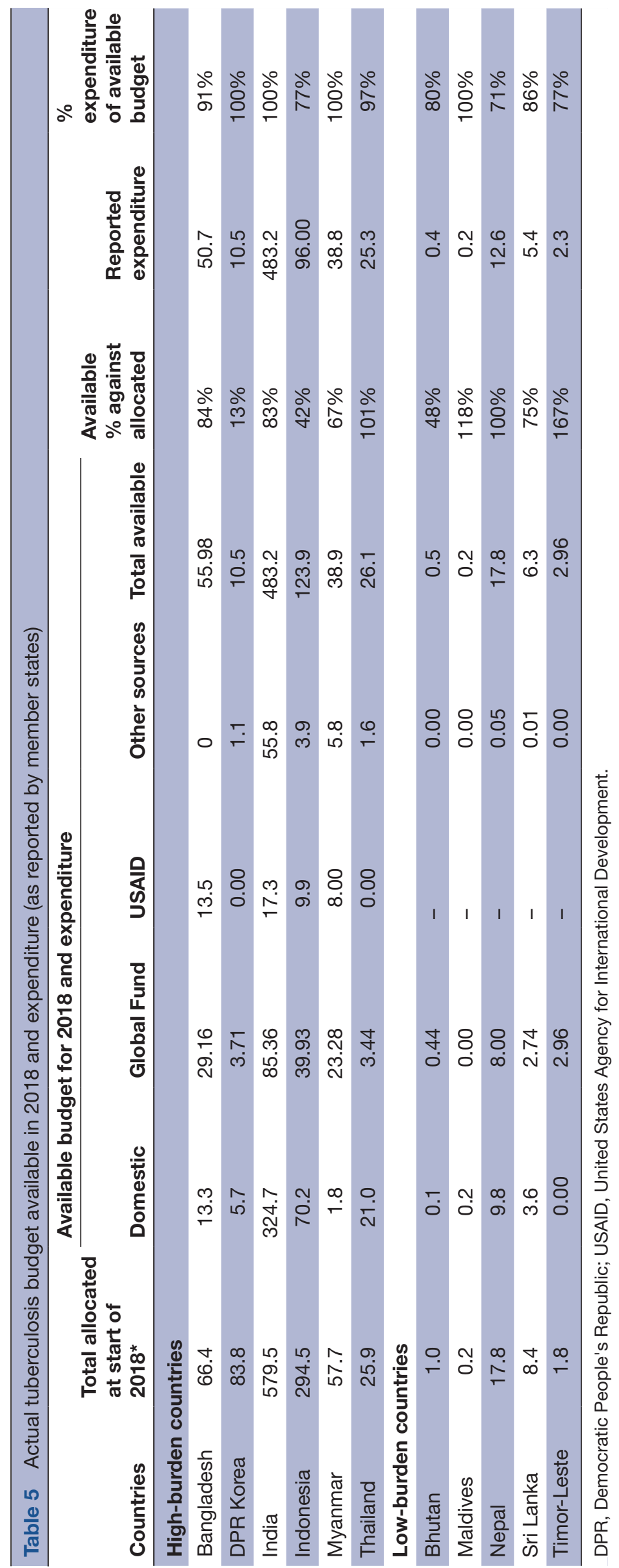

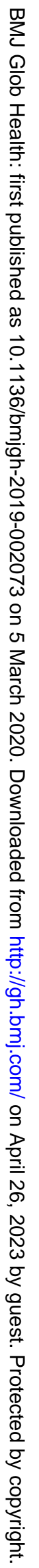




\begin{tabular}{|c|c|c|}
\hline Country & $\begin{array}{l}\text { Estimated needs } \\
\text { as per } \text { NSP }^{2}\end{array}$ & $\begin{array}{l}\text { Estimated needs } \\
\text { for ending TB }\end{array}$ \\
\hline Bangladesh & 66.44 & 102 \\
\hline Bhutan & 1.12 & 1.2 \\
\hline DPR Korea & 83.83 & 31.1 \\
\hline India & 579.51 & 1111 \\
\hline Indonesia & 294.49 & 402 \\
\hline Maldives & 0.19 & 1 \\
\hline Myanmar & 57.7 & 80 \\
\hline Nepal & 17.78 & 26 \\
\hline Sri Lanka & 8.4 & 32 \\
\hline Thailand & 25.86 & 117 \\
\hline Timor-Lest & & 4.91 \\
\hline SEAR & 1139 & 1937 \\
\hline
\end{tabular}

DPR, Democratic People's Republic; NSP, National Strategic Plan; SEAR, Southeast Asia Region.

for TB from domestic as well as donor agencies like the Global Fund and United States Agency for International Development.

Evidence is in favour of increased investments for ending TB. The benefits outweigh the increased costs. ${ }^{18}$ However, inaction comes with a hefty price. The risk of increased cases and catastrophic impacts of $\mathrm{TB}$ on the SEAR can only be combated with additional investments in the battle against TB. Unless the spending on TB increases, 'business as usual' spending on TB will cause it to remain one of the most serious threats in 2030, as it is today. Nevertheless, there has been a significant jump for budgets for TB between 2016 and 2018. The budget allocated by countries to end TB in 2018 was around $90 \%$ greater than that was available in 2016.

Studies have shown that there are several other ways to increase funding for TB care and prevention. These include but are not limited to insurance schemes, donor funding, engaging the private sector, innovative funding (such as Development Impact Bonds (DIB)), and resultsbased financing. An earlier analysis of funding for TB for 2002-2011 shows that $88 \%-92 \%$ of total funding was dominated by domestic funding-mostly from Brazil, Russia, India, China and South Africa (BRICS) and other middle-income countries. ${ }^{19}$ Increasing self-sufficiency in TB funding for BRICS is a lesson that can be adopted by other countries as well. Among SEAR countries, India has been most effective in raising funding for $\mathrm{TB}$ so far in this group. Countries like Bangladesh, India and Indonesia would have to further raise their allocations to the health sector in any case, being low public health spenders currently. Admittedly, health funding would vie with other priorities to garner a greater share of an expanded resource envelope, and within the health sector allocations, TB funding would compete with other priorities. While greater allocations to health may not necessarily translate into TB spending, it will go some way in meeting the resource need for TB as well. Bangladesh, in particular, may want to reduce its dependency on external resources for greater sustainability.

The Global Fund provides more than $65 \%$ of all international financing for TB since 2002. The Global Fund's investments focus in particular on countries with the highest disease burden. ${ }^{20}$ However, it is now being realised that donor funding would not be sufficient to fill the resource gap. Alternative and innovative financing models to support national government programmes would be required for sustainable financing. Many of the

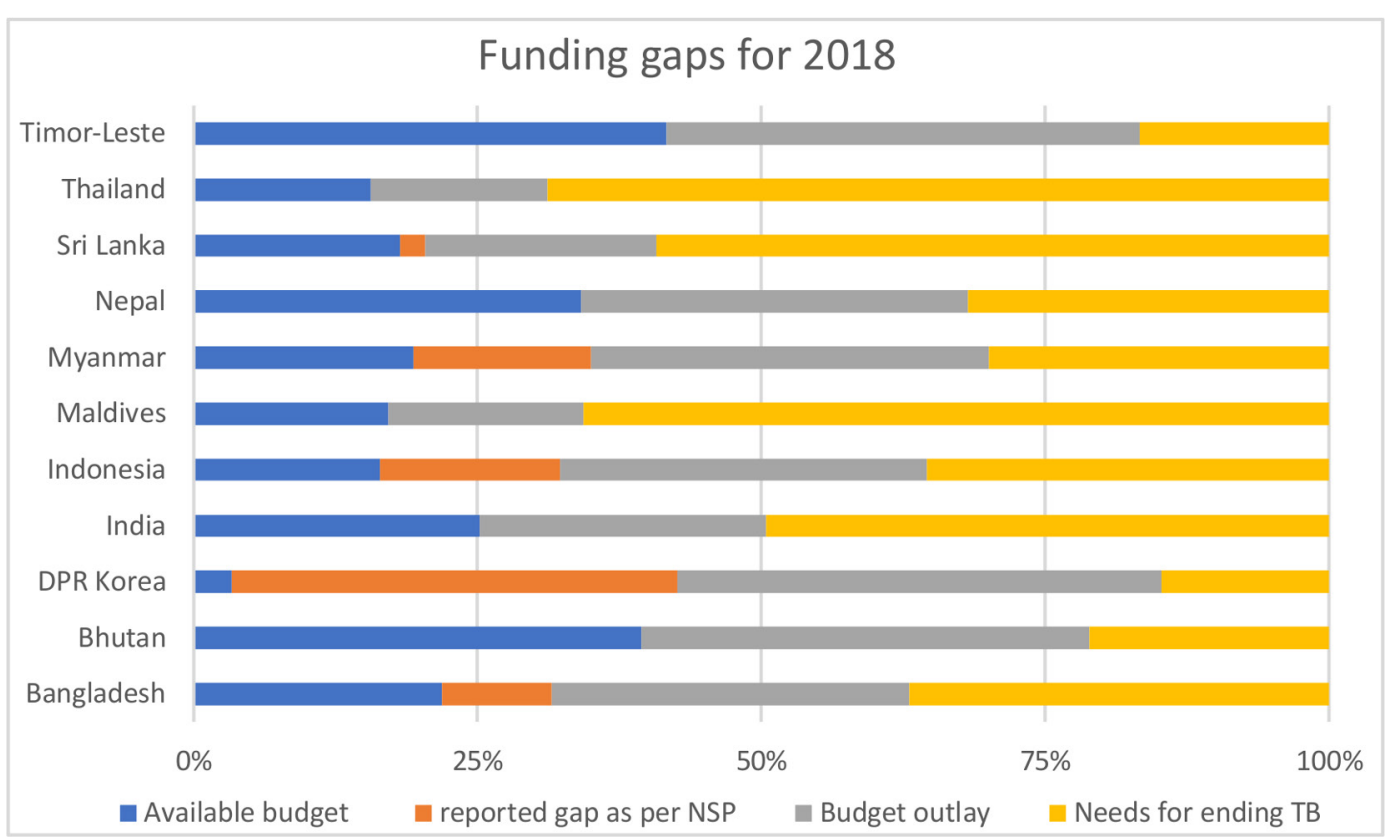

Figure 1 Resource gap for ending tuberculosis (TB) in Southeast Asia Region. DPR, Democratic People's Republic. 
SEAR countries are characterised by the significant presence of the private sector, including for TB. It is, therefore, strategic to involve the private sector in partnerships with the public sector in activities consistent with country priorities, in joint public-private missions so that government's resources are augmented both financially as well as in non-monetary terms. This would include all the major stakeholders in the private sector-physicians, pharmacists, clinics and hospitals. This would reduce to some extent the burden on the government to raise resources, financial and non-financial. For example, in India alone, optimising PSE can potentially avert 8 million deaths from TB between 2019 and $2045 .{ }^{8}$ The innovative models such as Enhanced Use of Quality Drugs and Utilization of Innovative Diagnostics for TB Management in the Private Sector contribute to increased case notifications from the private sector in India. ${ }^{21}$ However, such models need to be sustained for reaching end TB strategy targets.

There are two important lessons for countries in the SEAR: (1) front loading of investments is essential and in fact imperative for a comprehensive approach to battling TB, and (2) diversification of sources of funding is essential especially for those countries with a heavy TB burden even though Global Fund remains the largest international funder of TB control activities. As burden varies across countries, health spending also varies. This must be understood in the broader context of national investments in health. Those countries with low public sector spending and a high burden of TB need to prioritise TB within their constrained health budgets given the disproportionately high health and development impact (Bangladesh, India and Indonesia all spend less than $40 \%$ as part of public health spending). Challenges are likely to remain even in the event of rapid expansions in future funding: across the region, countries will need to strengthen their capacity to absorb these funds and spend them in the most efficient way. ${ }^{22}$

\section{CONCLUSION}

It is essential for countries to focus on other ways of raising funds as well. Countries will have to depend on the blended stream of financing-explore multiple sources of funding, especially for countries with a high disease burden. Here, their fiscal capacity, ability to forge partnerships with the private sector and relation with existing and new donors would be key factors. Financing focus would require a focus on new resources as well as managing existing resources.

Domestic financing is going to remain the most important source of finance for governments in this region, especially from the perspective of sustainability. There are many ways to explore additional domestic funding; an important channel will remain through taxes. Countries need to consider to what extent they can raise their tax revenues as a proportion of gross domestic product (GDP); middle-income countries and countries with fairly robust economic growth like India can certainly make additional efforts to increase their tax-GDP ratio so that the resource envelope can be expanded. Most of the SEAR countries have relatively low tax-GDP ratios that can certainly be raised if macroeconomic fundamentals are stable.

Strengthen financial protection and prepooling - many countries in the SEAR have been moving towards Universal Health Coverage (UHC) to improve financial protection. This would continue to be an essential tool of health financing and can help fund the components of the programme, like diagnostics and treatment. High direct and indirect costs of care hamper access and increase the risk of poor TB treatment outcomes. ${ }^{23}$ The new approach has to be consistent with the sustainable development goals on UHC, and it is critical that countries are able to think of TB funding within the envelope of UHC for some key components. WHO's post-2015 global TB strategy also explicitly highlights the key role of UHC and social protection.

Donor funding is going to continue to be a key source in low-income countries and has been an important financing source for global TB programmes, especially in low-income and middle-income countries. International development agencies have to work in tandem with each other and with national governments to catalyse additional resources for countries that are in critical need of external funding for their TB programmes. The cooperation will include technical support and help to ensure that countries are able to explore all sources of domestic financing and programmatic inputs.

Engagement of the private sector in TB programme is important to raise funding and to make the response more effective. In some countries, the private sector is mandated to invest some minimum amount in socially relevant activities under the Corporate Social Responsibility mandate. This should be used innovatively for augmenting resources within countries. ${ }^{24}$

Innovative financing, GAVI, the Vaccine Alliance and Global Fund are examples of new agencies that came into being based on essentially innovative financing approaches to mainly leverage non-governmental stakeholders, to raise resources for important health goals. However, there are other models of innovative financing that can be also used in the region. Most of these are methods to leverage the private sector for raising additional resources but can also involve other donors and funding agencies and the government.

- DIB - these are adapted from Social Impact Bonds that are being implemented in the UK and USA. These are usually contract with the public sector for an intervention that can improve social outcomes-'payfor-success' projects. An investor is usually involved, and the public sector passes on some of the savings to the investor. DIB is similar-the upfront funding can be from any source including private funders and donors and the remuneration can be by governments or other stakeholders. 
- Nando's-a restaurant chain has joined the United Against Malaria campaign to raise funds through a variety of ways including the sale of bracelets at its various restaurants.

- Other innovative models for raising revenues include a levy on air ticket sales and financial transactions that have been used by a number of African countries, ${ }^{25}$ auctioning/sales of emission permits. The International Finance Facility for Immunization is also a way of raising funds through bonds. ${ }^{26}$ Other innovations include schemes like Advance Market Commitments to provide incentives to develop new vaccines.

Results-based financing to improve the efficiency of spending and reduce the need for additional resources: in resource-constrained settings, it is critical to use the limited resources efficiently. There are examples of such mechanisms that can be applied in the region. Resultbased financing has worked well in many countries and mostly the examples are from the health sector, for example, health centre visits for preventive childhood care in Rwanda, a programme in Argentina to reduce neonatal mortality, a health and education programme in Indonesia to improve outcomes, Madhya Pradesh Higher Education programme, ${ }^{27}$ and so on. International organisations like the World Bank have been significantly involved in such programmes at the country level.

Twitter Vineet Bhatia @dr_vb, K Srikanth Reddy @srikanth_kreddy and Sandip Mandal @sandipmathmodel

Contributors The corresponding author SS conceptualised the analysis. SM and NA performed the modelling analysis. VB did the analysis and wrote the first draft. All other authors have contributed to the analysis and revising the manuscript, approved for submission.

Funding The authors have not declared a specific grant for this research from any funding agency in the public, commercial or not-for-profit sectors.

Competing interests None declared.

Patient consent for publication Not required.

Provenance and peer review Not commissioned; externally peer reviewed.

Data availability statement No additional data are available.

Open access This is an open access article distributed in accordance with the Creative Commons Attribution Non Commercial (CC BY-NC 4.0) license, which permits others to distribute, remix, adapt, build upon this work non-commercially, and license their derivative works on different terms, provided the original work is properly cited, appropriate credit is given, any changes made indicated, and the use is non-commercial. See: http://creativecommons.org/licenses/by-nc/4.0/.

ORCID iD

Swarup Sarkar http://orcid.org/0000-0001-9487-1955

\section{REFERENCES}

1 Nadda JP, Singh PK. New evidence of the tuberculosis burden in Asia demands national action. Lancet 2016;388:2217-9.

2 WHO. Global tuberculosis report 2019. Global tuberculosis report, 2019.

3 WHO SEARO. Ending TB: invest now or pay later, 2018.

4 WHO. Global tuberculosis report 2018. World Health Organization, 2018.
5 IHME. Findings from the global burden of disease study 2017. Seattle, WA: IHME, 2018.

6 WHO. The end TB strategy. Geneva: World Health Organisation, 2018.

7 Paul D. Governments Pledge US\$15 Billion a Year for TB by 2022, 2018.

8 Reid MJA, Arinaminpathy N, Bloom A, et al. Building a tuberculosisfree world: the Lancet Commission on tuberculosis. Lancet 2019;393:1331-84.

9 Arinaminpathy N, Mandal S, Bhatia V, et al. Strategies for ending tuberculosis in the South-East Asian region: a modelling approach. Indian J Med Res 2019;149:517.

10 Baltussen R, Floyd K, Dye C. Cost effectiveness analysis of strategies for tuberculosis control in developing countries. BMJ 2005;331:1364.

11 Atun R, Chang AY, Ogbuoji O, et al. Long-term financing needs for HIV control in sub-Saharan Africa in 2015-2050: a modelling study. BMJ Open 2016;6:e009656.

12 Menzies NA, Gomez GB, Bozzani F, et al. Cost-effectiveness and resource implications of aggressive action on tuberculosis in China, India, and South Africa: a combined analysis of nine models. Lancet Glob Health 2016;4:e816-26.

13 WHO. Latent tuberculosis infection: updated and consolidated guidelines for programmatic management. World Health Organization, 2018.

14 WHO. Tuberculosis patient cost surveys: a handbook. Geneva, Switzerland: WHO, 2017.

15 Verguet S, Riumallo-Herl C, Gomez GB, et al. Catastrophic costs potentially averted by tuberculosis control in India and South Africa: a modelling study. Lancet Glob Health 2017;5:e1123-32.

16 World Bank. Current health expenditure per capita (current US\$), 2019.

17 Arinaminpathy N, Batra D, Khaparde S, et al. The number of privately treated tuberculosis cases in India: an estimation from drug sales data. Lancet Infect Dis 2016;16:1255-60.

18 Jha P, Gajalakshmi V, Gupta PC, et al. Prospective study of one million deaths in India: rationale, design, and validation results. PLOS Med 2005:3:e18.

19 WHO. World health statistics 2012. Geneva: World Health Organisation, 2012.

20 Muniyandi M, Ramachandran R, Balasubramanian R. Costs to patients with tuberculosis treated under DOTS programme. Indian Journal of Tuberculosis 2005;52:188-96.

21 Ananthakrishnan R, Richardson M D'Arcy, van den Hof S, et al. Successfully engaging private providers to improve diagnosis, notification, and treatment of TB and drug-resistant TB: the EQUIP public-private model in Chennai, India. Glob Health Sci Pract 2019;7:41-53.

22 Lu C, Michaud CM, Khan K, et al. Absorptive capacity and disbursements by the global fund to fight AIDS, tuberculosis and malaria: analysis of grant implementation. Lancet 2006:368:483-8.

23 Kamolratanakul P, Sawert H, Kongsin S, et al. Economic impact of tuberculosis at the household level. Int J Tuberc Lung Dis 1999;3:596-602.

24 Lönnroth K, Aung T, Maung W, et al. Social franchising of TB care through private GPs in Myanmar: an assessment of treatment results, access, equity and financial protection. Health Policy Plan 2007;22:156-66.

25 Tanimura T, Jaramillo E, Weil D, et al. Financial burden for tuberculosis patients in low- and middle-income countries: a systematic review. Eur Respir J 2014;43:1763-75.

26 Vassal A. Benefits and Costs of TB Control for the Post-2015 Development Agenda. In: Lomborg B, ed. Prioritizing development: a cost benefit analysis of the United nations' sustainable development goals. Cambridge: Cambridge University Press, 2018: 255-65.

27 The Economist. The economics of optimism: the debate heats up about what goals the world should set itself for 2030 New York the Economist, 2015. Available: https://www.economist.com/financeand-economics/2015/01/22/the-economics-of-optimism [Accessed 15 Aug 2019].

28 Pai M, Dewan P. Testing and treating the missing millions with tuberculosis. PLoS Med 2015;12:e1001805.

29 WHO. Bending the curve-ending TB: annual report 2017. In: Regional office for south-east Asia, new Delhi, India, 2017. 